\title{
Physical mapping shows that the unstable oxytetracycline gene cluster of Streptomyces rimosus lies close to one end of the linear chromosome
}

\author{
Kenan Pandza, ${ }^{1,2}+$ Guido Pfalzer, ${ }^{2}$ John Cullum ${ }^{2}$ and Daslav Hranueli' \\ Author for correspondence: John Cullum. Tel: +49631205 4062. Fax: +496312054090. \\ e-mail: cullum@rhrk.uni-kl.de
}

1 PLIVA d.d., Research Institute, Prilaz baruna Filipovica 25, 10000 Zagreb, Republic of Croatia

2 LB Genetik, Universităt Kaiserslautern, Postfach 3049, D-67653 Kaiserslautern, Germany

\begin{abstract}
A restriction map of the $8 \mathrm{Mb}$ linear chromosome of Streptomyces rimosus R6-501 was constructed for the enzymes Asel (13 fragments) and Dral (7 fragments). Linking clones for all 12 Asel sites and 5 of the 6 Dral sites were isolated. The chromosome has terminal inverted repeats of $550 \mathrm{~kb}$, which are the longest yet reported for a Streptomyces species. The oxytetracycline gene cluster lies about $600 \mathrm{~kb}$ from one end, which might account for its frequent spontaneous amplification and deletion. Several other markers were localized on the chromosome (dnaA and recA, the rrn operons, the attachment site for PSAM2 and prophages RP2 and RP3). Comparison of the conserved markers with the map of Streptomyces coelicolor A3(2) suggested there are differences in genome organization between the two species.
\end{abstract}

Keywords: Streptomyces rimosus, physical map, linear chromosome, terminal repeats, oxytetracycline

\section{INTRODUCTION}

The genes for the biosynthesis of the commercially important antibiotic oxytetracycline (OTC) in Streptomyces rimosus lie in a cluster of about $30 \mathrm{~kb}$ in size flanked by two resistance genes. This pattern is seen both in the 'Pfizer strain' (S. rimosus M4018 lineage; Butler et al., 1989) and in the 'Zagreb strain' (S. rimosus R6 lineage; Perić, 1995). OTC production in S. rimosus R6 is genetically unstable and some spontaneous mutants carry large-scale DNA rearrangements involving the OTC-cluster (Gravius et al., 1993). Class II mutants showed large $(>450 \mathrm{~kb}$ ) deletions that remove the whole cluster, whereas class III mutants showed reiteration of the cluster resulting in higher production of, and resistance to, OTC.

Investigations in Streptomyces lividans 66 (Redenbach et al., 1993) and Streptomyces ambofaciens (Leblond et al., 1996) showed that unstable regions subject to deletion and amplification are located close to the ends

†Present address: Department of Genetics, Stanford University School of Medicine, Stanford, CA 94305-5120, USA.

Abbreviation: OTC, oxytetracycline. of the linear chromosomes in these species. These two species have inverted repeats of $30 \mathrm{~kb}$ and $210 \mathrm{~kb}$, respectively, at the ends of their chromosomes, which are about $8 \mathrm{Mb}$ in size. These observations suggested that the OTC-cluster might also lie near one end of the chromosome in $S$. rimosus. This would also have consequences for the formation of plasmid primes: it has been suggested that the plasmid pPZG103 which carries the OTC-cluster might have been formed by a single cross-over between the linear plasmid pPZG101 and the chromosome of S. rimosus (Gravius et al., 1994b; Hranueli et al., 1995).

In this paper, we report the establishment of a physical map of the chromosome of S. rimosus $\mathrm{R} 6$ and the mapping of several loci, including the OTC-cluster. This allows comparison with the map of Streptomyces coelicolor A3(2) (Redenbach et al., 1996), which is interesting because the two species are not closely related [S. coelicolor A3(2) belongs to the $S$. griseoruber cluster of Williams et al., 1983; E. M. H. Wellington, personal communication].

\section{METHODS}

Bacterial strains, phages and plasmids. $S$. rimosus R6 strains 500 and 501 and phages RP2 and RP3 are described by Hranueli et al. (1979) and Rausch et al. (1993). The linear 
chromosome map of S. lividans 66 strain ZX7 and the derivative with a circular chromosome, strain MR02 are described by Redenbach et al. (1993). S. coelicolor A3(2) strain 1147 is described by Hopwood et al. (1985). The construction of the cosmid gene bank of strain S. rimosus R6-501 is described by Rausch et al. (1993); the same methods were used to construct the cosmid gene bank of the AseI-J band. The vector used (sCos-1; Evans et al., 1989) has T3 and T7 promoter sequences flanking the insert and the insert is also flanked by EcoRI sites. pBR328 (Bolivar et al., 1977) was used to construct the AseI-linking library in Escherichia coli strain XL1-Blue (Bullock et al., 1987).

The following plasmids were used to localize loci on the physical map: pTS55 (Smokvina et al., 1991), used to localize att-pSAM2; pIM (Pujić, 1992), containing an $8.8 \mathrm{~kb} \mathrm{BamHI}$ fragment carrying the whole copy of the $r r n$ operon of $S$. rimosus $\mathrm{R} 7$; pFF911 and pFF914 (Musialowski et al., 1994), carrying the $d$ naA-oriC region of $S$. coelicolor $\mathrm{A} 3(2)$; pBN104 (Nußbaumer \& Wohlleben, 1994), carrying the recA gene of $S$. lividans 66; and pMT2005 (Ali-Dunkrah et al., 1990), carrying the gal operon of S. lividans 66 .

Molecular genetic techniques. Media and growth conditions, total DNA preparation, plasmid DNA preparation, restriction digests, agarose gel electrophoresis, Southern blots and DNA labelling were done as described by Gravius et al. (1993). Exonuclease III digestions were carried out similarly to restriction digests using the buffer recommended by the manufacturer (Boehringer Mannheim). Digoxigenin-labelled RNA using T3 or T7 RNA polymerase was done according to the manufacturer's instructions (Boehringer Mannheim). Before T3 or T7 labelling clones were doubly digested with EcoRI and SalI (which cuts frequently in Streptomyces DNA) so as to achieve specific labelling of the ends of the inserts.

DNA was prepared in agarose blocks, digested with restriction enzymes, separated on a Bio-Rad CHEF DRII apparatus and transferred to membranes by Southern blotting as described by Gravius et al. (1993). The pulse programme for separating intact chromosomes was $50 \mathrm{~V}, 192 \mathrm{~h}$, with a $1 \mathrm{~h}$ constant pulse time; other programmes are indicated in the figure legends. Bands were eluted from PFGE gels as described by Gravius $e t$ al. (1994b).

To construct the Asel-linking libraries, total DNA of $S$. rimosus R6-501 was digested with Sal I or PstI and the digested DNA ligated at a low DNA concentration $\left(<1 \mu \mathrm{g} \mathrm{ml}^{-1}\right)$ to promote intramolecular circularization. The religated DNA was digested with AseI and ligated together with alkalinephosphatase-treated AseI-restricted DNA of pBR328. The ligation mixtures were introduced into $E$. coli XL1-Blue by electroporation using a BioRad GENEPULSER apparatus and conditions recommended by the manufacturer (voltage $2500 \mathrm{~V}$, resistance $200 \Omega$, capacitance $25 \mu \mathrm{F}$ which gave a time constant, $\tau$, of $4 \cdot 5-4 \cdot 8 \mathrm{~ms})$. Transformants were selected on chloramphenicol-containing medium $\left(50 \mu \mathrm{g} \mathrm{ml}^{-1}\right)$ and tested for ampicillin $\left(100 \mu \mathrm{g} \mathrm{ml}^{-1}\right)$ resistance by replica plating.

\section{RESULTS}

\section{Size of the chromosome}

Undigested DNA from $S$. rimosus R6-501 was subjected to PFGE using a pulse programme developed to allow visualization of the linear chromosome of S. lividans 66 (Lin et al., 1993). A band was produced that migrated
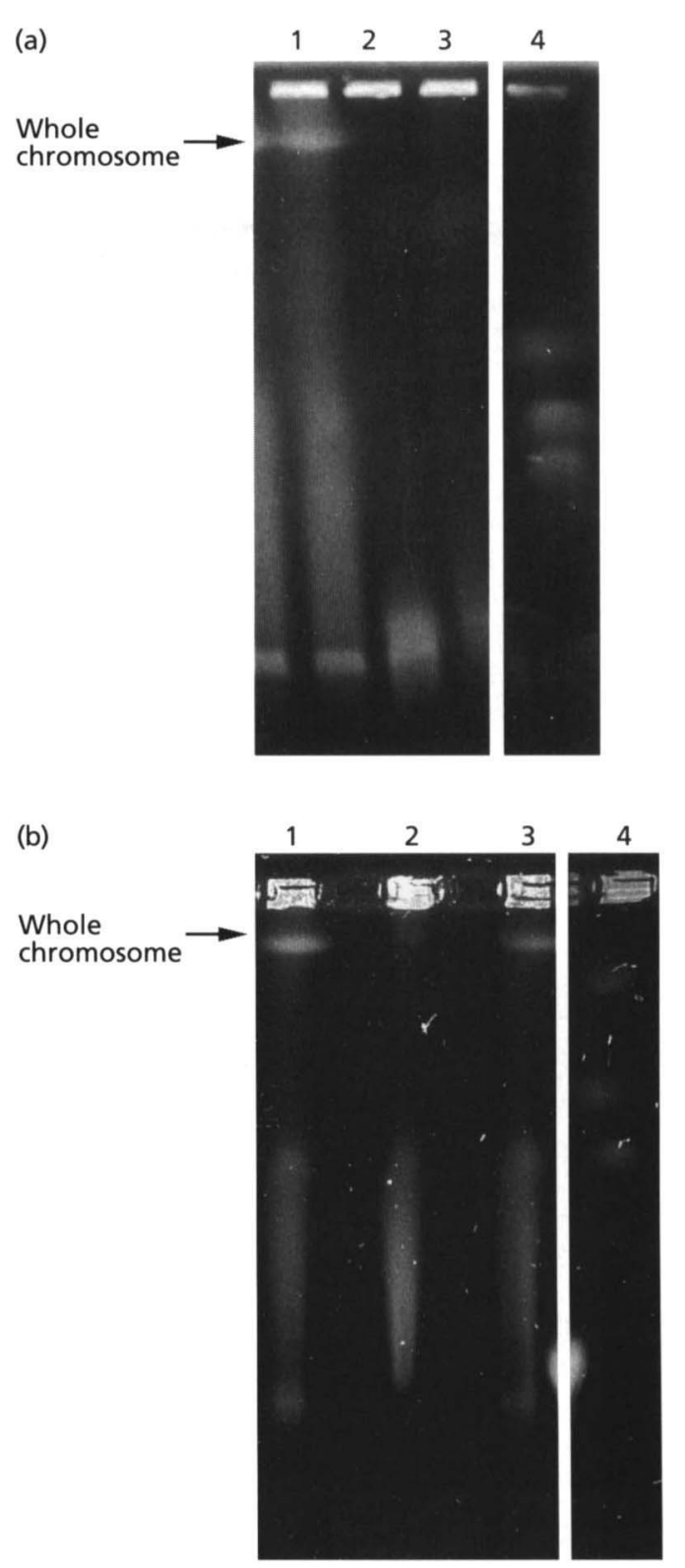

Fig. 1. PFGE of undigested DNA of Streptomyces species. Pulse programme: $50 \mathrm{~V}, 192 \mathrm{~h}, 1 \mathrm{~h}$ constant pulse time. The bands corresponding to whole chromosomes are marked. (a) Tracks: 1 , S. rimosus R6-501; 2-3, S. rimosus R6-501 treated with $100 \mathrm{U}$ and $200 \mathrm{U}$, respectively, exonuclease III; 4, chromosomes of Schiz. pombe. (b) Tracks: 1, S. coelicolor A3(2) strain 1147; $2, S$. lividans 66 strain MR02; 3, S. lividans 66, strain ZX7; 4, chromosomes of Schiz. pombe.

slower than the largest chromosome of Schizosaccharomyces pombe (Fig. 1a, track 4). Similar results were obtained with S. coelicolor A3(2) and S. lividans 66 (Fig. $1 \mathrm{~b}$, tracks 1 and 3), which have linear chromosomes (Lin et al., 1993), whereas a mutant (MR02) of S. lividans that possesses a circular chromosome (Redenbach et al., 1993) does not produce a high-molecular-mass band (Fig. 1b, track 2). Treatment of the DNA of S. rimosus 

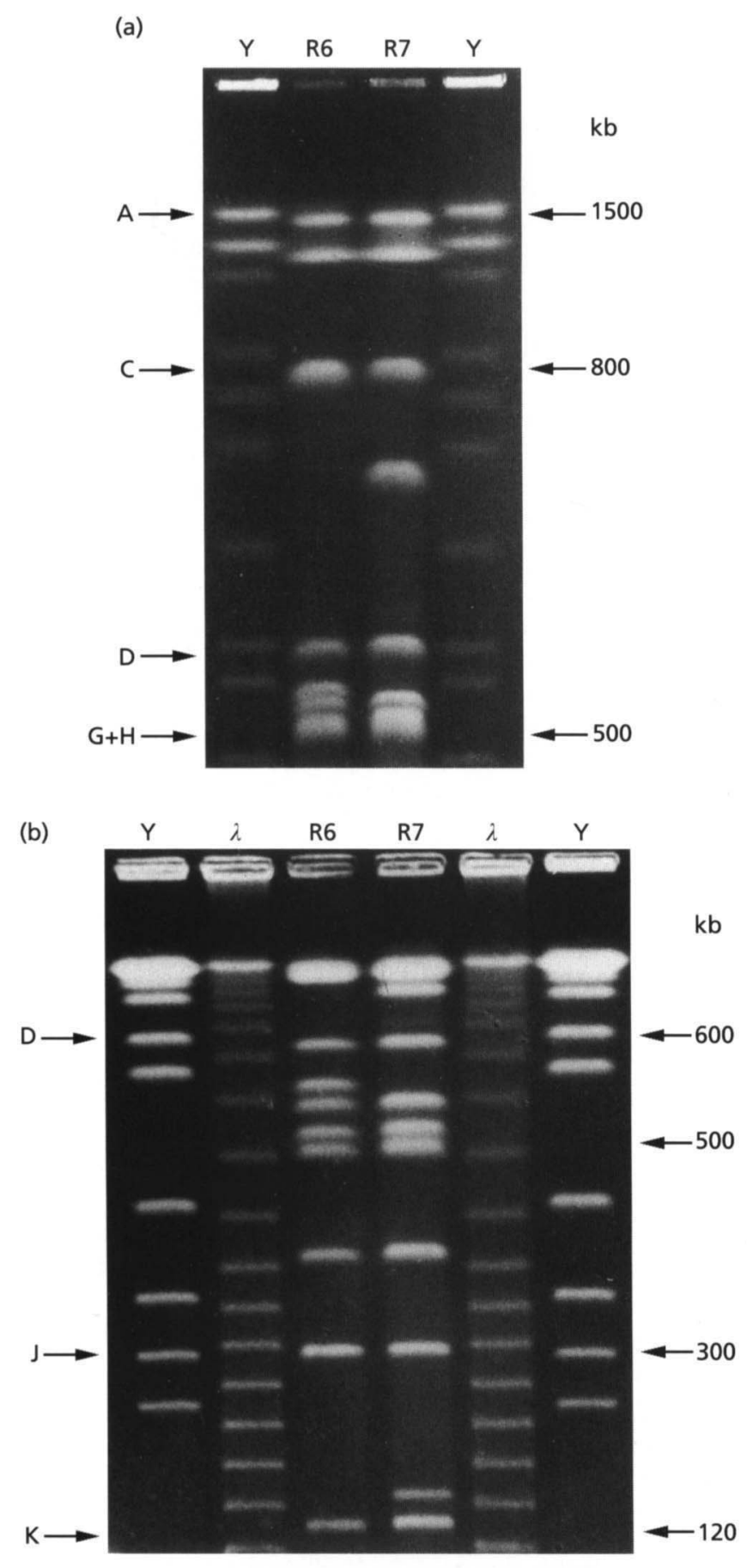

Fig. 2. Chromosomal DNA of S. rimosus strains R6-501 and R7 (ATCC 10970) digested with Asel. Plasmid DNA was removed by a prerun. Tracks: R6, S. rimosus R6-501; R7, S. rimosus ATCC $10970 ; Y$, chromosomes of Sacch. cerevisiae; $\lambda$, lambda ladders. (a) Pulse programme: $160 \mathrm{~V}, 60 \mathrm{~h}$, ramp of pulse times 70-80 s. (b) Pulse programme: $160 \mathrm{~V}, 36 \mathrm{~h}$, ramp of pulse times $40-50 \mathrm{~s}$.

with exonuclease III (Fig. 1a, tracks 2 and 3) leads to the loss of the slowly migrating band, supporting the idea that it is a large linear molecule rather than a smaller circular molecule.
Total DNA preparations of $S$. rimosus in agarose blocks were subjected to a prerun to remove the DNA of the linear plasmid pPZG101 (Gravius et al., 1994b). The resulting chromosomal DNA preparations were digested with the enzymes AseI, DraI, SspI and XbaI and separated by PFGE. Fig. 2 shows the AseI digests run with two different pulse programmes to optimize separation in different parts of the molecular mass range; 11 fragments can be seen. The sizes of the larger fragments $(>500 \mathrm{~kb})$ were estimated (Table 1) by comparison with lambda ladders and the chromosomes of Saccharomyces cerevisiae. As smaller fragments of high $\mathrm{G}+\mathrm{C}$-content migrate faster than similar-sized fragments of lower G+C-content (Gravius et al., 1994a), the fragment sizes were recalculated relative to high $\mathrm{G}+\mathrm{C}$-markers as described by Gravius et al. (1994b). The high $\mathrm{G}+\mathrm{C}$ effect is particularly striking for the AseI-K fragment of $120 \mathrm{~kb}$ (Table 1) which migrates faster than the $100 \mathrm{~kb}$ lambda-dimer (Fig. 2b, tracks labelled $\lambda$ and R6). Scanning of gel photographs with a densitometer suggested that the $\mathrm{C}$ band and the $\mathrm{J}$ band consisted of double fragments (Table 1). The OTCcluster lies on one of the $\mathrm{C}$ fragments and analysis of deletions affecting the cluster had already suggested that there were two distinct fragments of this size (Gravius et al., 1993). The DraI digest could be separated into seven distinct fragments (Table 1). Comparison of the restriction patterns with total DNA (without a prerun to remove pPZG101) showed an identical pattern except for the addition of the three known Asel fragments and two known DraI fragments (Gravius et al., 1994b) of pPZG101. Table 1 also shows the sizes of the $S s p I$ and $X b a I$ fragments, which because of their larger numbers (21 and 26 fragments, respectively) were not used for mapping of the entire chromosome. The sums of the fragment sizes for the four enzymes were consistent with each other, only varying between 7735 and $8090 \mathrm{~kb}$. Thus, S. rimosus R6-501 has a chromosome size of about $8 \mathrm{Mb}$, similar to that of other Streptomyces species (Kieser et al., 1992; Leblond et al., 1993, 1996; Lezhava et al., 1995). In addition, DNA from another $S$. rimosus strain (R7) was digested with the same enzymes (Fig. 2). The digestion patterns were clearly related, but there were also differences between the two strains.

\section{Isolation of linking clones}

We used a cosmid gene bank of S. rimosus R6-501 (Rausch et al., 1993) in the vector sCos-1 (Evans et al., 1989). Cosmid DNA was prepared from 1600 clones and digested with the enzyme AseI. The vector contains two AseI sites, so if no AseI site is present in the insert, two bands of $1.73 \mathrm{~kb}$ and $45-50 \mathrm{~kb}$ are seen. If the insert contains one AseI site then three bands are seen. Using this method 47 cosmids containing 7 different AseI sites were isolated. Similarly, 24 clones containing 5 different DraI sites were isolated.

Another strategy to isolate AseI-linking clones used a method adapted from Poustka \& Lehrach (1986). 288 potential Asel-linking clones were isolated. These were 
Table 1. Sizes of the Dral, Asel, Sspl and Xbal restriction fragments of the S. rimosus R6-501 chromosome

The sum of the fragment sizes is given in parentheses at the bottom of the respective columns.

\begin{tabular}{|c|c|c|c|c|c|}
\hline \multicolumn{2}{|c|}{ DraI } & \multicolumn{2}{|c|}{ AseI } & \multirow{2}{*}{$\begin{array}{c}\text { SspI } \\
\text { Size }(\mathbf{k b})\end{array}$} & \multirow{2}{*}{$\begin{array}{c}\boldsymbol{X b a I} \\
\text { Size }(\mathbf{k b})\end{array}$} \\
\hline Fragment & Size $(\mathbf{k b})$ & Fragment & Size $(\mathbf{k b})$ & & \\
\hline I & 2400 & $\mathbf{A}$ & 1540 & 1400 & 1120 \\
\hline II & 1670 & B & 1120 & 1000 & 800 \\
\hline III & 1230 & $\mathrm{Cl}$ & 795 & 745 & 680 \\
\hline IV & 1180 & $\mathrm{C} 2$ & 795 & 745 & 610 \\
\hline $\mathrm{V}$ & 850 & D & 600 & 710 & 510 \\
\hline VI & 290 & $\mathrm{E}$ & $\mathbf{5 5 0}$ & 500 & 480 \\
\hline \multirow[t]{21}{*}{ VII } & 270 & $\mathbf{F}$ & 525 & 500 & 415 \\
\hline & $(8070)$ & G & 510 & 445 & 350 \\
\hline & & $\mathbf{H}$ & 500 & 415 & 320 \\
\hline & & I & 415 & 280 & 280 \\
\hline & & $\mathbf{J}$ & 300 & 280 & 230 \\
\hline & & $\mathbf{J}$ & 300 & 270 & 230 \\
\hline & & $\mathbf{K}$ & 120 & 205 & 200 \\
\hline & & & $(7890)$ & 160 & 200 \\
\hline & & & & 95 & 195 \\
\hline & & & & 80 & 185 \\
\hline & & & & 65 & 160 \\
\hline & & & & 60 & 155 \\
\hline & & & & 52 & 145 \\
\hline & & & & 45 & 115 \\
\hline & & & & 38 & 90 \\
\hline & & & & $(8090)$ & 85 \\
\hline & & & & & 80 \\
\hline & & & & & 40 \\
\hline & & & & & 31 \\
\hline & & & & & 29 \\
\hline & & & & & (7735) \\
\hline
\end{tabular}

used for colony hybridization against a pool of the existing Asel-linking cosmids to exclude duplicates. This yielded four new classes of AseI-linking clones.

\section{Construction of the restriction map of the chromosome}

Representative AseI- and DraI-linking clones were used as hybridization probes against Southern blots of PFGE gels of AseI and DraI single digests and double digests of chromosomal DNA. In most cases the linking clones for a particular enzyme hybridized to two different fragments obtained after digestion with that enzyme (e.g. see Fig. 3, tracks 1-2). Thus, C-A11 hybridized to AseI-A and K, C-A41 to AseI-G and H, C-A5 to AseI-H and I, C-AF2 to AseI-B and F, C-A23 to AseI-D and F, and C-A21 to AseI-D and E. Each of the DraI-linking clones shown in the map (Fig. 4) hybridized only to the corresponding two DraI fragments. In the case of the double band AseI-C, C-AE8 hybridized to AseI-C and K,
C-AB4 to AseI-A and C, and C-A9 to AseI-C and G; the two AseI-C fragments were distinguished by hybridizing to digestions of the class II mutant MV7 (Gravius et al., 1993), which carries a deletion affecting the AseI-C1 fragment that carries the OTC-cluster; this assigned $\mathrm{C}$ $\mathrm{AB} 4$ and $\mathrm{C}-\mathrm{A} 9$ to the AseI-C2 fragment, and C-AE8 to the AseI-C1 fragment. The Asel-linking clone C-AE6 hybridized with the AseI-A, B, C and I bands and also gave very weak hybridization with the AseI-H band (data not shown). DNA from this clone was doubly digested with AseI and SalI and the two AseI-SalI fragments of the insert eluted from an agarose gel. When one of these fragments was hybridized with a Southern blot of a PFGE gel, only the AseI-I band hybridized, whereas the other fragment hybridized to the other four Ase I bands (A, B, C and $\mathrm{H}$ ). This shows that sequences at one end of the insert in C-AE6 are derived from AseII and suggests that there is a repeated sequence on the other side of the AseI site in C-AE6. As both linking clones at the ends of the AseI-A, C2 and H fragments were already known and further analysis (see below) 


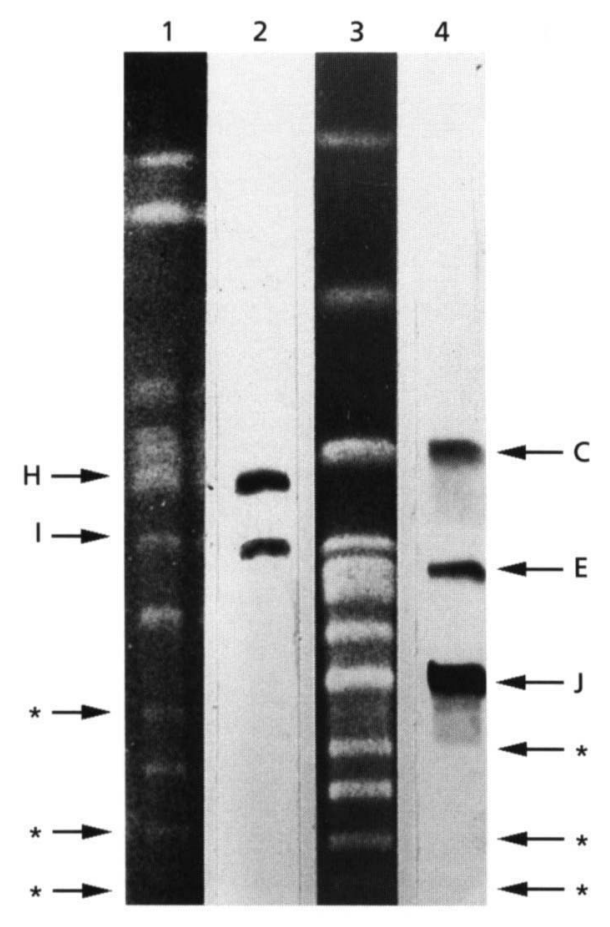

Fig. 3. Hybridization with linking clones. Total DNA of $S$. rimosus R6-501 was digested with Asel and separated by PFGE (pulse programmes: track $1,200 \mathrm{~V}, 28 \mathrm{~h}$, ramp of pulse times 60-130 s; track 3, 200 V, $30 \mathrm{~h}$, ramp of pulse times 80-130 s). The bands marked with an asterisk are derived from the linear plasmid pPZG101. Southern blots of the digests in tracks 1 and 3 were hybridized with digoxigenin-labelled DNA from the linking clone C-A5 (track 2) and C-A4 (track 4).

defined the second linking clone for AseI-C1 (C-A4) it was concluded that C-AE6 was the linking clone between the AseI-B and I fragments. The insert in C-AE6 did not cross-hybridize with any of the other linking clones and hybridization experiments with a plasmid pIM (Pujić, 1992) carrying an rRNA operon of $S$. rimosus showed that the repeated sequence was not part of an rRNA operon.

A second AseI-linking clone that hybridized to more than two fragments (Fig. 3, tracks 3-4) was clone C-A4, which hybridized to the AseI-C, E and J fragments. Since the densitometer results had suggested that AseI-J was a double band and there were no other AseI-linking cosmids that hybridized with the AseI-J band, it was suspected that the AseI-J fragment might be contained within a large duplication. When a map of the chromosome was constructed according to this hypothesis, a linear map resulted with the two copies of the AseI-J fragment at the ends (Fig. 4). The linear map is supported by the failure to isolate linking clones connecting the presumed end fragments (the two AseI-J fragments and the DraI-A and B fragments) and a more detailed study of the terminal inverted repeats below. As expected, the linking clone C-A4 hybridized to both the DraI-I and II fragments. This means that all 12 of the
AseI-linking clones and 5 out of 6 of the Dral-linking clones had been isolated.

\section{Analysis of the inverted repeats with cosmid clones}

The agarose containing the $300 \mathrm{~kb}$ AseI-J band was excised from a gel. DNA was eluted, partially digested with $M b o I$ and used to construct a cosmid bank in sCos-1. Forty clones were obtained and were ordered by cross-hybridization. This yielded a contig in fragment AseI-J which was spanned by 9 cosmids starting with the linking clone C-A4 (Fig. 5). One of the clones (J-39) contained a BfrI site which lies $180 \mathrm{~kb}$ from the chromosome end. This means that the most distal cosmid (J-28) is still $50-100 \mathrm{~kb}$ away from the chromosome end.

The AseI-linking clone C-A4 contains an $\mathrm{XbaI}$ restriction site about $10 \mathrm{~kb}$ distant from, and proximal to, the AseI site. When the clone was used as a hybridization probe against $X b a I$ digests of chromosomal DNA, fragments of $415 \mathrm{~kb}$ and $300 \mathrm{~kb}$ hybridized. The $415 \mathrm{~kb}$ fragment is the fragment that carries the OTC-cluster (Gravius et al., 1993). This fragment was isolated from a PFGE gel, labelled with digoxigenin and used as a probe for colony hybridizations of the $S$. rimosus gene bank (S. Pandza and others, unpublished results). It was possible to construct a contig of 10 overlapping cosmid clones starting from the AseI-linking clone C-A4 up to cosmid C-136 (Fig. 5). These clones were used as hybridization probes against Southern blots of AseI digests (data not shown) and hybridize to both the AseI$\mathrm{C}$ and $\mathrm{E}$ bands. A complication arose when four cosmids that cross-hybridized with C-136 were examined. When Southern blots of EcoRI digests of three of the cosmids (C-19, C-86 and C-88) were hybridized with a C-136 probe, there was only one hybridizing fragment of $5 \mathrm{~kb}$ in size (data not shown). A non-hybridizing band from each cosmid was used as a hybridization probe against Southern blots of an AseI digest of chromosomal DNA. In each of the three cases, only the AseI-A fragment hybridized, which suggests the presence of a repeated element in cosmid C-136, which is also present in the Asel-A fragment. The fourth cosmid (C-61) showed a longer homology with C-136, with only two EcoRI fragments of $9 \mathrm{~kb}$ and $5 \mathrm{~kb}$ not hybridizing. C-61 hybridized to the AseI-C band alone which means that it lies outside the inverted repeat in the AseI-C1 fragment. In order to find a cosmid that carries the end of the inverted repeat in the AseI-E fragment, C-136 was used to isolate a further four cosmids from the gene bank which did not hybridize with C-62, the distal cosmid overlapping C-136. Restriction fragments which did not hybridize with C-136 were identified in each cosmid and used as hybridization probes against Southern blots of Asel digests of total DNA. One of these cosmids (C-123) contained a $6 \mathrm{~kb}$ EcoRI fragment that hybridized only with the Asel-E fragment. Thus, the ends of the inverted repeat in the AseI-C1 and AseI-E fragments lie within C136 and $\mathrm{C}-123$, respectively. The inverted repeat is about $550 \mathrm{~kb}$ long (Fig. 5). 


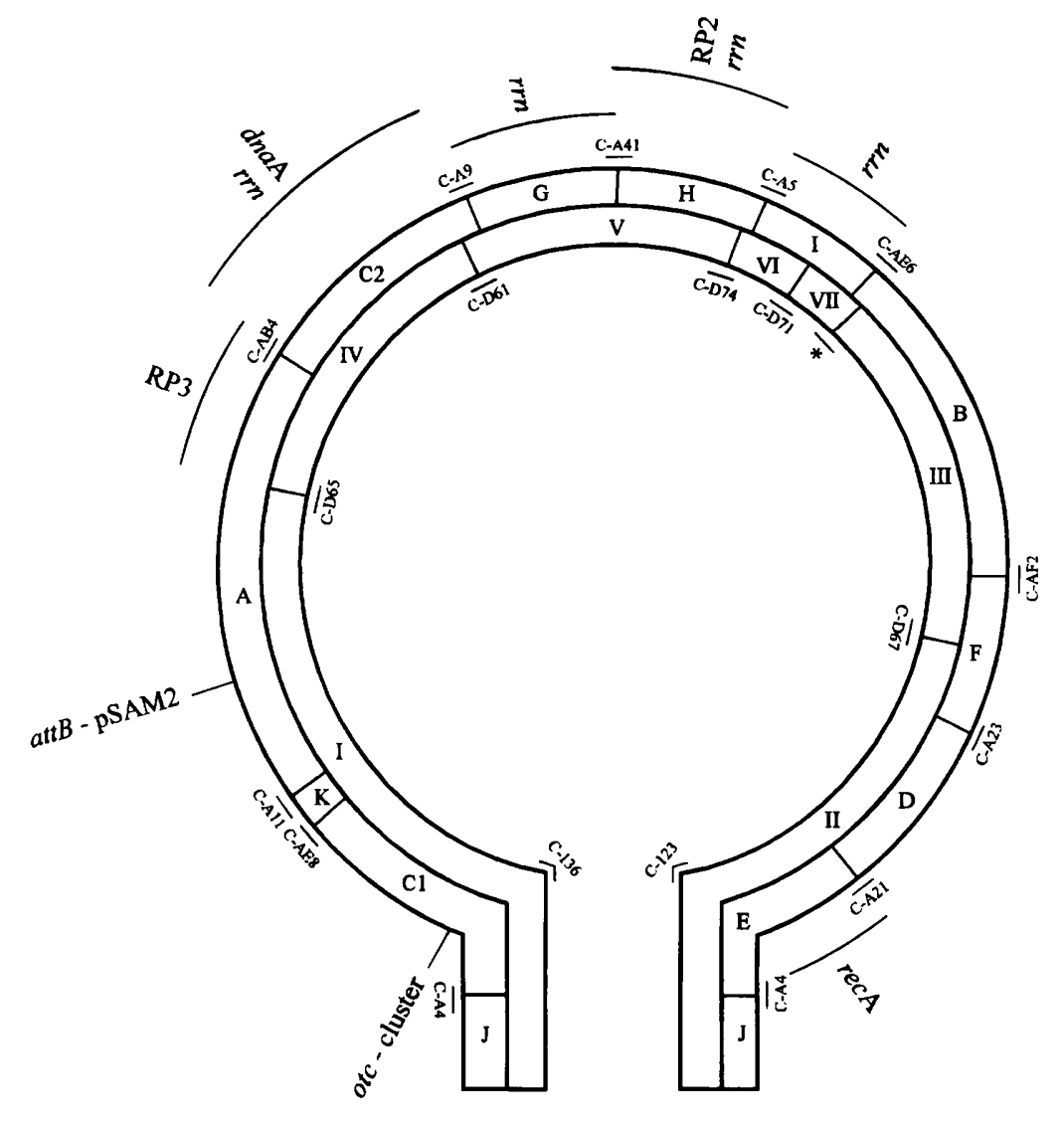

Chromosomal ends
Fig. 4. Restriction map of the chromosome of S. rimosus R6-501 for the enzymes Asel (outer arc) and Dral (inner arc). The terminal inverted repeats are drawn as a stem structure. The numbers of the linking clones are indicated adjacent to the corresponding restriction sites; the missing Dral linking clone is indicated by an asterisk. The cosmid clones carrying the ends of the terminal inverted repeats $(C-136$ and $C-123)$ are also indicated. The OTC-cluster and attB-pSAM2 have been precisely localized. The other markers have only been localized to particular Asel and Dral fragments.

\section{Mapping of genetic loci}

Previous work (Gravius et al., 1993) had shown that genes of the OTC-cluster hybridize only with the $415 \mathrm{~kb}$ $\mathrm{Xbal}$ fragment and the $795 \mathrm{~kb}$ Ase $\mathrm{I}-\mathrm{C} 1$ fragment. As the genes do not hybridize with the AseI-E fragment at the other chromosome end or with the cosmids from the terminal inverted repeat (data not shown), the cluster must lie between the end of the terminal inverted repeat and the $\mathrm{XbaI}$ site (i.e. $550-720 \mathrm{~kb}$ from the chromosome end; Fig. 5). In a $B f_{r} I$ digest the cluster was localized to a $490 \mathrm{~kb}$ BfrI fragment (data not shown), which overlaps with the $415 \mathrm{~kb} \mathrm{Xbal}$ fragment. Thus, the $30 \mathrm{~kb}$ long OTC-cluster lies in the $120 \mathrm{~kb}$ region between the end of the terminal inverted repeat and the $B f_{r} I$ site (i.e. $550-670 \mathrm{~kb}$ from the chromosome end; Fig. 5).

$\mathrm{RP} 2$ and RP3 are prophages that are integrated into the chromosome of S. rimosus R6 (Rausch et al., 1993). Hybridization experiments with DNA from phages RP2 and RP3 localized the prophages to the AseI-H and DraI-V and to the AseI-A and DraI-IV fragments, respectively (Fig. 4). In strain R6-500 (Rausch et al., 1993), which has been cured of the RP2 prophage, the AseI-H band was missing and was replaced by a fragment about $65 \mathrm{~kb}$ smaller, as expected for a simple excision event. The vector pTS55, which is based on the integrating plasmid pSAM2 (Smokvina et al., 1991), was introduced into $S$. rimosus (J. Pigac, personal communication). Digestion of DNA from a strain containing pTS55 showed that the AseI-A band had disappeared and been replaced by two bands of about $1 \mathrm{Mb}$ and $600 \mathrm{~kb}$ (data not shown); this is expected, because of the presence of an AseI site in pTS55. Southern blots of the digests were hybridized with the two Asel-A-linking clones, which showed that the $600 \mathrm{~kb}$ fragment was linked to AseI-K. This localized attB-pSAM2 precisely on the map. The rRNA genes were localized to AseI and DraI fragments using plasmid pIM (Pujić, 1992) as a hybridization probe. Four hybridizing bands were seen with each enzyme (AseI-C, G, H and I, DraI-IV, V, VI and VII, respectively). This allows approximate localization of the rrn operons on the map. The two plasmids pFF911 and pFF914 (Musialowski et al., 1994), which carry the dnaA-oriC region of $S$. coelicolor A3(2), were used as hybridization probes. Both showed hybridization to the AseI-C and DraI-IV bands, which allows the approximate localization of the region on the map (Fig. 4). Plasmid pBN104, which carries the recA gene of S. lividans 66 (Nußbaumer \& Wohlleben, 1994), showed strong hybridization to the AseI-E and DraI-II fragments. A plasmid (pMT2005, Ali-Dunkrah et al., 1990) carrying the gal operon of S. lividans 66 did not give any hybridization signals with $S$. rimosus DNA. 

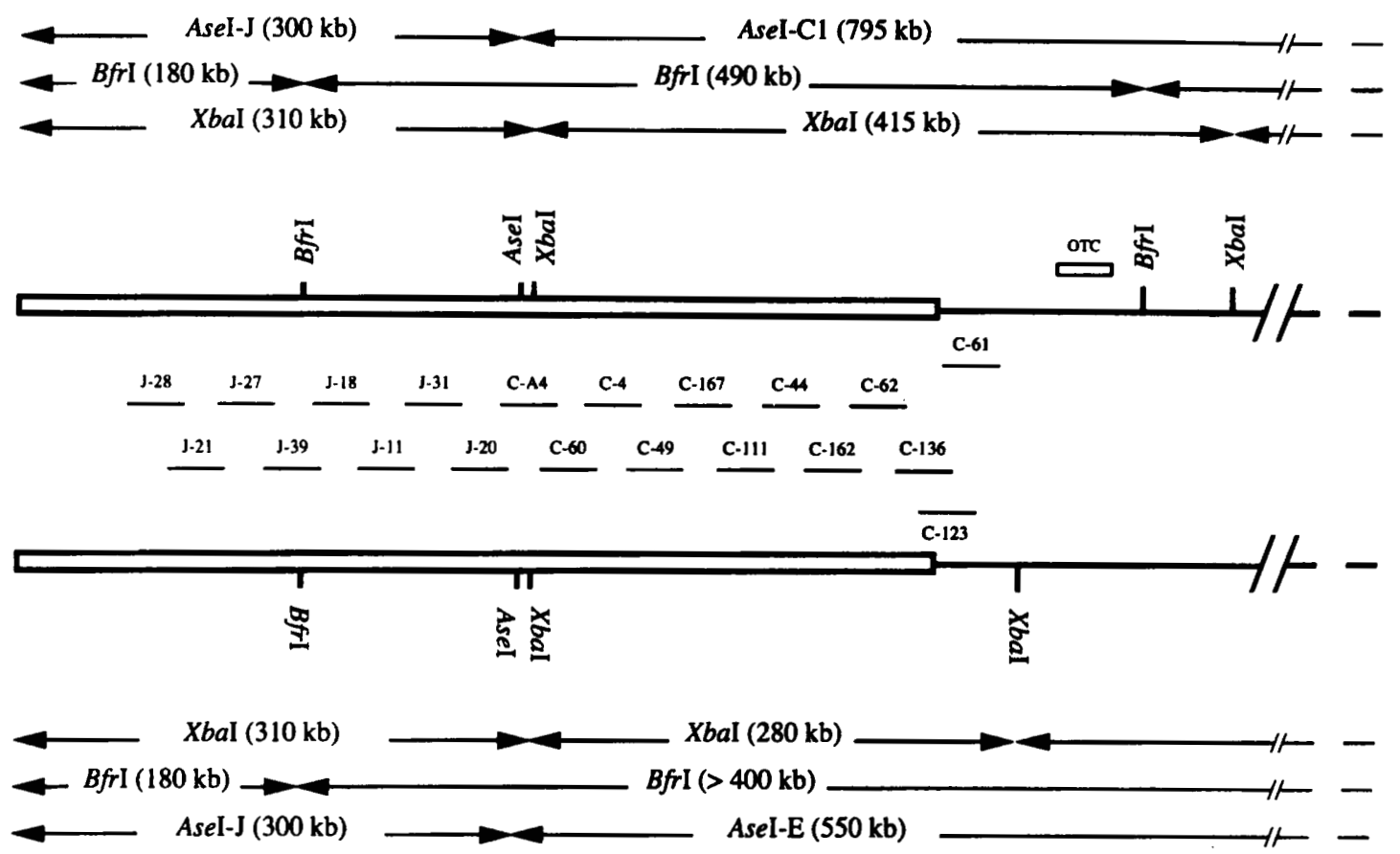

\section{R-TIR}

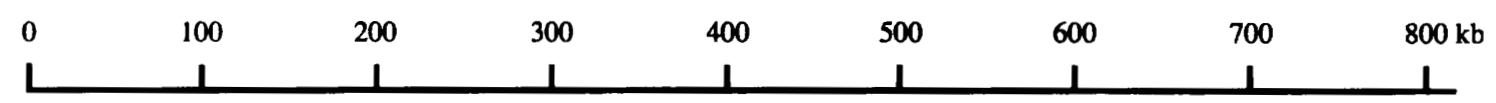

Fig. 5. Structure of the terminal inverted repeats. The cosmids from J-28 up to C-62 are in the inverted repeat and cannot be assigned to a particular chromosome end. C-136 and C-61 belong to the Asel-C1 end, whereas C-123 carries the end of the inverted repeat at the Asel-E end.

\section{DISCUSSION}

The chromosome of $S$. rimosus $\mathrm{R} 6$ is about $8 \mathrm{Mb}$ in size, which is similar to the values obtained with $S$. coelicolor A3(2) (Kieser et al., 1992), S. lividans 66 (Leblond et al., 1993), S. griseus (Lezhava et al., 1995) and S. ambofaciens (Leblond et al., 1996). The ends of the chromosome are inverted repeats of about $550 \mathrm{~kb}$ in size, which is considerably longer than those reported in other Streptomyces species $(22-210 \mathrm{~kb})$. The lengths of the inverted repeats of linear plasmids also vary markedly and it has been speculated that recombination events lead to evolution in the length of the repeats (Kalkus $e t$ al., 1993; Gravius et al., 1994b; Hranueli et al., 1995). It is interesting to note that the cosmid clone carrying one end of the inverted repeat (C-136) cross-hybridized with cosmids from the AseI-A fragment. This might indicate the presence of a transposable element, which could be involved in the formation of the extremely long inverted repeat structure.

The OTC-cluster lies $550-670 \mathrm{~kb}$ from one end of the chromosome (Figs 4 and 5), which probably accounts for the frequent DNA rearrangements affecting this region (Gravius et al., 1993). More detailed restriction analysis of the cluster $(N$. Peric $\&$ D. Hranueli, unpublished results) showed that the otrB resistance gene was closest to the chromosome end. The increased copy number of the OTC-region seen in class III mutants might result from amplification events similar to those which affect sequences near the chromosome ends in other species (Redenbach et al., 1993; Leblond et al., 1996). Deletion of the OTC-cluster in class II mutants could either involve an internal deletion not affecting the chromosome end as observed in S. ambofaciens (Leblond et al., 1996), or loss of one chromosome end as observed in S. lividans (Rauland et al., 1995). Deletions arising from circularization of the chromosome with loss of both ends (as observed in both S. ambofaciens and S. lividans) is unlikely, because the deletion mutants retain the Asel-J band (Gravius et al., 1993). However, in some auxotrophic mutants (strains 605, 609 and 615; Gravius et al., 1994b) the AseI-J band is missing so it is possible that these strains have circular chromosomes.

Gravius et al. (1994b) reported that the integration of linear plasmids into the chromosome of S. rimosus can 
preserve at least one free plasmid end and a linear plasmid prime carrying the OTC-region was also observed. It was speculated that such events involved single cross-overs between linear plasmids and the linear chromosome. The location of the OTC-cluster near one end of the chromosome makes this more plausible and further results supporting this idea will be presented in a future paper.

S. ambofaciens and $S$. coelicolor A3(2) show a very similar location of genes on the physical map (Leblond et al., 1996), which is not surprising given their relatively close taxonomic relationship. The recent localization of many genes to an ordered cosmid gene bank of $S$. coelicolor A3(2) (Redenbach et al., 1996) provides precise locations, which can be compared with the $S$. rimosus results. Whereas the oriC-dnaA region is located almost exactly in the centre of the $S$. coelicolor A3(2) chromosome, it is asymmetrically placed in $S$. rimosus (from 34 to $44 \%$ of the chromosome from the end depending on the exact location within the AseI-C2 restriction fragment). The recA gene of $S$. rimosus is close to one end of the chromosome (550-850 kb away), whereas in S. coelicolor $\mathrm{A} 3(2)$ it is $2 \mathrm{Mb}$ away from the closer end. In $S$. rimosus, the $r r n$ operons are in the central region of the chromosome, with no operon being within $2755 \mathrm{~kb}$ and $3095 \mathrm{~kb}$ of the respective ends. This contrasts with $S$. coelicolor A3(2) where the $r r n C$ operon is about $1.4 \mathrm{Mb}$ from one end and the $r r n E$ operon about $2.1 \mathrm{Mb}$ from the other end. The $r r n E$ operon is close to the recA gene, whereas there is no $r r n$ operon close to the recA gene in S. rimosus (Fig. 4). In S. rimosus, attBpSAM2 (which is the gene for a tRNA ${ }^{\text {pro }}$; Mazodier et al., 1990) is about $1.8 \mathrm{Mb}$ from the chromosome end whereas in S. coelicolor A3(2) it is near the centre of the chromosome. These comparisons suggest that the genetic organization of $S$. rimosus may differ significantly from that of $S$. coelicolor A3(2). This is seemingly in contradiction with results from the comparison of the genetic maps, which suggested similar organization (Pigac \& Alačević, 1979). However, it must be remembered that the auxotrophic markers used were not characterized biochemically in either species, so it is not clear if every marker used was homologous between the two species. Resolution of this question awaits physical characterization of more markers in S. rimosus.

\section{ACKNOWLEDGEMENTS}

We thank Fiona Flett, Vera Gamulin, Jasenka Pigac and Wolfgang Wohlleben for providing plasmids and strains, and Matthias Redenbach and Annette Arnold for help with PFGE of whole chromosomes. We thank the DAAD for providing a studentship (to K.P.) and the International Bureau KfA-Jülich and DLR-Bonn of the BMBF, Federal Republic of Germany and the Ministry of Science and Technology, Republic of Croatia for supporting the cooperation of the two laboratories.

\section{REFERENCES}

Ali-Dunkrah, U., Kendall, K. \& Cullum, J. (1990). Spontaneous mutations in the galactose operons of Streptomyces coelicolor
A3(2) and Streptomyces lividans 66. J Basic Microbiol 30, 307-312.

Bolivar, F., Rodrigez, R. L., Green, P. J., Betlach, M. C., Heyneker, H. L., Boyer, H. W., Costa, J. H. \& Falkow, S. (1977). Construction and characterization of new cloning vehicles. II. A multipurpose cloning system. Gene 2, 95-113.

Bullock, W. O., Fernandez, J. M. \& Short, J. M. (1987). XL1-B: a high efficiency plasmid transforming recA Escherichia coli strain with $\beta$-galactosidase selection. Biotechniques 5, 376-379.

Butler, M. J., Friend, E. J., Hunter, I. S., Kaczmarek, F. S., Sudgen, D. A. \& Warren, M. (1989). Molecular cloning of resistance gene and architecture of a linked gene cluster involved in the biosynthesis of tetracycline by Streptomyces rimosus. Mol Gen Genet 215, 231-238.

Evans, G. A., Lewis, K. \& Rothenberg, B. E. (1989). High efficiency vectors for cosmid microcloning and genomic analysis. Gene 79, 9-20.

Gravius, B., Bezmalinovic, T., Hranueli, D. \& Cullum, J. (1993). Genetic instability and strain degeneration in Streptomyces rimosus. Appl Environ Microbiol 59, 2220-2228.

Gravius, B., Cullum, J. \& Hranueli, D. (1994a). High G + C-content DNA markers for pulsed-field gel electrophoresis. Biotechniques $16,52$.

Gravius, B., Glocker, D., Pigac, J., Pandža, K., Hranueli, D. \& Cullum, H. (1994b). The $387 \mathrm{~kb}$ linear plasmid pPZG101 of Streptomyces rimosus and its interactions with the chromosome. Microbiology 140, 2271-2277.

Hopwood, D. A., Bibb, M. J., Chater, K. F., Kieser, T., Bruton, C. J., Kieser, H. M., Lydiate, D. J., Smith, C. P., Ward, J. M. \& Schrempf, H. (1985). Genetic Manipulation of Streptomyces : a Laboratory Manual. Norwich: The John Innes Foundation.

Hranueli, D., Pigac, J. \& Vešligaj, M. (1979). Characterization and persistence of actinophage RP2 isolated from Streptomyces rimosus ATCC 10970. J Gen Microbiol 114, 295-303.

Hranueli, D., Pandza, K., Biukovic, G., Gravius, B. \& Cullum, J. (1995). Interaction of linear plasmid with Streptomyces rimosus chromosome: evidence for the linearity of chromosomal DNA. Croat Chem Acta 68, 581-588.

Kalkus, J., Dörrie, C., Fischer, D., Reh, M. \& Schlegel, H. G. (1993). The giant linear plasmid pHG207 from Rhodococcus sp. encoding hydrogen auxotrophy: characterization of the plasmid and its termini. J Gen Microbiol 139, 2055-2065.

Kieser, H., Kieser, T. \& Hopwood, D. A. (1992). A combined genetic and physical map of the Streptomyces coelicolor A3(2) chromosome. J Bacteriol 174, 5496-5507.

Leblond, P., Redenbach, M. \& Cullum, J. (1993). Physical map of the Streptomyces lividans 66 genome and comparison with that of the related strain Streptomyces coelicolor A3(2). J Bacteriol 175, 3422-3429.

Leblond, P., Fischer, G., Francou, F.-X., Berger, F., Guerineau, M. \& Decaris, B. (1996). The unstable region of Streptomyces ambofaciens includes $210 \mathrm{~kb}$ terminal inverted repeats flanking the extremities of the linear chromosomal DNA. Mol Microbiol 19, 261-271.

Lezhava, A., Mizukami, T., Kajitani, T., Kameoka, D., Redenbach, M., Shinkawa, H., Nimi, O. \& Kinashi, H. (1995). Physical map of the linear chromosome of Streptomyces griseus. J Bacteriol 177, 6492-6498.

Lin, Y.-S., Kieser, H. M., Hopwood, D. A. \& Chen, C. W. (1993). The chromosomal DNA of Streptomyces lividans 66 is linear. Mol Microbiol 10, 923-933.

Mazodier, P., Thompson, C. \& Boccard, F. (1990). The chromo- 
somal integration site of the Streptomyces element pSAM2 overlaps a putative $t R N A$ gene conserved among actinomycetes. Mol Gen Genet 222, 431-434.

Musialowski, M. S., Flett, F., Scott, G. B., Hobbs, G., Smith, C. P. \& Oliver, S. G. (1994). Functional evidence that the principal DNA replication origin of the Streptomyces coelicolor chromosome is close to the dnaA-gyrB region. J Bacteriol 176, 5123-5125.

Nußbaumer, B. \& Wohlleben, W. (1994). Identification, isolation and sequencing of the recA gene of Streptomyces lividans TK24. FEMS Microbiol Lett 118, 57-64.

Peric, N. (1995). Izolacija cjelovite nakupine otc gena soja Streptomyces rimosus R6. MSc thesis, University of Zagreb.

Pigac, J. \& Alačevic, M. (1979). Mapping of oxytetracycline genes in Streptomyces rimosus. Period Biol 81, 575-582.

Poustka, A. \& Lehrach, H. (1986). Jumping libraries and linking libraries: the next generation of molecular tools in mammalian genetics. Trends Genet 2, 174-179.

Pujic, P. (1992). Struktura rrnF operona za ribosomske RNA iz bakterije Streptomyces rimosus. MSc thesis, University of Zagreb.

Rauland, U., Glocker, I., Redenbach, M. \& Cullum, J. (1995). DNA amplifications and deletions in Streptomyces lividans 66 and the loss of one end of the linear chromosome. Mol Gen Genet 246, $37-44$.
Rausch, H., Vešligaj, M., Połta, D., Biukovic, G., Pigac, J., Cullum, J., Schmieger, H. \& Hranueli, D. (1993). The temperate phages RP2 and RP3 of Streptomyces rimosus. J Gen Microbiol 139, 2517-2524.

Redenbach, M., Flett, F., Piendl, W., Glocker, I., Rauland, U., Wafzig, O., Kliem, R., Leblond, P. \& Cullum, J. (1993). The Streptomyces lividans 66 chromosome contains a $1 \mathrm{Mb}$ deletogenic region flanked by two amplifiable regions. Mol Gen Genet 241, 255-262.

Redenbach, M., Kieser, H. M., Denapaite, D., Eichner, A., Cullum, J., Kinashi, H. \& Hopwood, D. A. (1996). A set of ordered cosmids and a detailed genetic and physical map of the $8 \mathrm{Mb}$ Streptomyces coelicolor A3(2) chromosome. Mol Microbiol 21, 77-96.

Smokvina, T., Boccard, F., Pernodet, J.-L., Friedmann, A. \& Guérineau, M. (1991). Functional analysis of the Streptomyces ambofaciens element pSAM2. Plasmid 25, 40-52.

Williams, S. T., Goodfellow, M., Alderson, G., Wellington, E. M. H., Sneath, P. H. A. \& Sackin, M. J. (1983). Numerical classification of Streptomyces and related genera. J Gen Microbiol 129, 1743-1813.

Received 22 November 1996; accepted 14 January 1997. 